\title{
Cazadores sin presas, horticultores sin tierra. Una aproximación a las formas actuales de producción y acceso al alimento en el pueblo indígena Hitnu
}

\section{Hunters with no prey, horticulturists with no land. An approach to the current ways of production and access to food by the Hitnu indigenous people}

\author{
iD Johnatan Andrés Soto-Aguirre ${ }^{1}$
}

\begin{abstract}
Resumen
El pueblo indígena Hitnu padece una grave crisis alimentaria que durante los últimos años se ha agudizado por múltiples factores. El propósito de este texto es presentar un panorama amplio multi-causal de la situación actual de la producción y acceso a los alimentos de este grupo indígena, con el objetivo de ahondar en la comprensión de la situación que afronta y aportar elementos que permitan superar ciertos abordajes investigativos e intervenciones sociales reduccionistas, en la medida que se concentran en un solo ámbito de la problemática. En el texto se expondrá la necesidad de considerar: los actuales patrones de organización social, las diferencias inter-generacionales, los usos del suelo, la variación del territorio indígena, formas de clasificación social, las relaciones inter-étnicas, la injerencia de grupos externos (transnacionales, guerrillas), las estrechas relaciones económicas con el mundo no indígena, entre otros elementos que permiten complejizar las aproximaciones a la crisis alimentaria. A partir de los datos recabados por medio del trabajo de campo, la etnografía y la revisión bibliográfica, se busca evidenciar la gravedad de la crisis alimentaria del pueblo Hitnu, un caso, como muchos otros en el país, que hace palpable la enorme vulnerabilidad de las comunidades étnicas.
\end{abstract}

Palabras Clave: Crisis alimentaria; producción de alimentos; acceso a los alimentos; Hitnu

\begin{abstract}
The Hitnu indigenous people suffer from a serious food crisis that has been sharpened by many factors in recent years. The purpose of this text is to present a multi-causal overview of the current situation of the production and access to food by this indigenous group. The purpose is to understand the situation that they are facing, and to contribute
\end{abstract}

Tipología: Artículo de investigación científica y tecnológica

Recibido: 06/02/2017

Evaluado: $17 / 04 / 2017$

Aceptado: 01/06/2017

Disponible en línea: 01/07/2017

Como citar este artículo: Soto-Aguirre, J.A. (2017). Cazadores sin presas, horticultores sin tierra. Una aproximación a las formas actuales de producción y acceso al alimento en el pueblo indígena hitnu. Jangwa Pana, 16 (2), 179 - 196. DOI: http://dx.doi. org/10.21676/16574923.2129

1. Antropólogo. Universidad de Antioquia. Investigador independiente. Colombia. Correo electrónico: ezsotto@gmail.com. ORCID ID: 0000-0002-7553-4512. 
analytic elements that allow to overcome certain investigative approaches and reductionist social interventions, in so far as they concentrate on a single area of the problem. The article will state the need of considering: the current patterns of social organization, inter-generational differences, land uses, the variation of indigenous territory, types of social classification, inter-ethnic relationships, the interference of external groups (Multinational Corporations, guerrillas), the close economic relations with the non-indigenous world, among other elements that allow us to approach this complex food crisis. The severity of the Hitnu people's food crisis will be highlighted based on the data collected through fieldwork, ethnography, and bibliographical review. This is one case, among many others in the country, that makes apparent the enormous vulnerability of the Ethnic communities.

Keywords: Food crisis; production of food; access to food; Hitnu

\section{Introducción}

- Son las comunidades indígenas autárquicas? ¿Puede una población indígena pequeña contar con 4.611 hectáreas de tierra y carecer de alimento suficiente para satisfacer sus necesidades alimentarias básicas? ¿Es posible que una comunidad con animales domésticos no genere procesos reproductivos que lleven a mantener una oferta permanente de proteína animal? ¿Cómo explicar la escasez de alimento en una comunidad? ¿Resuelve la entrega de alimentos por parte del Estado la escasez de alimento en una comunidad? ¿La seguridad alimentaria cimentada en la entrega de mercados regularmente soluciona una crisis alimentaria?

Los territorios que ocupan las comunidades indígenas son concebidos por muchos sectores del país como paraísos - idea reforzada además por los programas de turismo nacional - en los que el agua, el alimento, la fauna y la flora en general son abundantes, ecosistemas mágicos, en donde los indígenas, en una relación armoniosa, suplen sus necesidades con un mínimo esfuerzo y en perfecto equilibrio con la naturaleza.

Ejemplos de esta visión paradisiaca de la tierra indígena y de la autosuficiencia que deberían tener las comunidades, fue el debate que hace menos de una década el Gobierno Nacional generó al afirmar que los comunidades indígenas eran los mayores terratenientes del país al poseer el $27 \%$ de las 115 millones de hectáreas con las que cuenta Colombia (Posso,
2008), dando a entender que las demandas de las comunidades indígenas por más tierra no procedían y eran injustificadas; en esta misma dirección el gobierno actual, haciendo caso omiso a las solicitudes de tierra por parte de organizaciones indígenas, aprobó el proyecto de ley que da espacio a las Zonas de Interés de Desarrollo Rural (ZIDRES), que permitirán que la agroindustria acumule baldíos y legalicen acumulaciones anteriores $^{2}$ (OXFAM, 2015).

Lejos de la autarquía indígena, la crisis alimentaria de las comunidades étnicas se profundiza. De acuerdo con el Ministerio de Salud y Protección Social (2016) durante el periodo 2002 2015 fallecieron 6,216 niños menores de 5 años por enfermedades asociadas a la desnutrición en todo el país, el 55\% pertenecían a grupos indígenas. "Durante el año 2016 se registraron 101 muertes de niños menores de cinco años por la misma causa, cincuenta y cuatro de ellos eran indígenas" ${ }^{3}$ (INS, 2016, p. 34). Las cifras indican que la prevalencia de desnutrición en el país tiende a ser mayor en grupos que se autorreconocen como comunidades étnicas y en familias campesinas que habitan los sectores rurales del territorio nacional.

En lo que concierne específicamente a los Hitnu, investigaciones del Instituto Colombiano de

\footnotetext{
2. Los terrenos baldíos son propiedad de la nación, para su adjudicación se establecen unos topes en la Resolución 041 de 1996 (Unidad Agrícola Familiar o UAF) y disposiciones de la Ley 160 de 1994; muchos baldíos son ocupados, pero su posesión no hace propietario al poseedor. La Ley ZIDRES permitiría acumular baldíos por encima de la UAF y además posibilitaría que todo lo que hubiera ocurrido antes de la Ley 160 de 1994 quedaría legalizado.

3. La fecha de corte para el año 2016 fue el 21 de diciembre.
} 
Bienestar Familiar han demostrado la gravedad de la situación nutricional de este grupo indígena, cerca del $84,4 \%$ de los niños, niñas y adolescentes valorados presentan casos de desnutrición (Burgos, 2011); y el suministro de alimento depende cada vez más, como se mostrará más adelante, de la asistencia alimentaria estatal.

Además de la grave problemática alrededor de la desnutrición en el pueblo Hitnu, preocupa que los enfoques de investigación con los que se estudia este grupo desde la antropología, centren sus análisis en variables endógenas, aproximaciones investigativas que conciben los territorios $y$ sociedades indígenas como unidades insulares (Friedemman \& Arocha, 1982; Lobo-Guerrero \& Herrera, 1989), o en enfoques unidireccionales donde lo no-indígena constituye, casi de forma invariable, una amenaza para la identidad étnica (Burgos, 2011). Ambos enfoques impiden comprender las múltiples articulaciones que se establecen en el diario vivir de las comunidades indígenas para resolver aspectos vitales en la producción y acceso al alimento.

Es indispensable reconocer que las aproximaciones teóricas y metodológicas que se realizan desde la antropología tienen efecto en las acciones que adopten actores sociales y estatales en la realidad. El propósito de este texto es presentar un panorama amplio multi-causal de la situación actual de la producción y acceso a los alimentos en este grupo indígena con el objetivo de ahondar en la comprensión de la situación que afrontan y aportar elementos que permitan superar los abordajes investigativos y las acciones de intervención reduccionistas. Para lograr dicho propósito es necesario considerar: los actuales patrones de organización social, las diferencias inter-generacionales, las formas de clasificación social, los usos del suelo, la variación del territorio indígena, las relaciones inter-étnicas, la injerencia de grupos externos, las estrechas relaciones económicas con el mundo no-indígena, entre otros elementos que permiten complejizar las aproximaciones a la crisis alimentaria.

\section{Materiales y métodos}

La información que se presenta en este texto fue producto de temporadas de investigación en terreno durante cinco meses, agosto a diciembre del año 2015; además del corpus etnográfico recolectado, el artículo incluye referencias de fuentes secundarías e históricas que fueron sistematizadas durante el año 2016.

El trabajo de campo se llevó a cabo en los resguardos San José del Lipa y La Vorágine, ubicados en el municipio de Arauca. No se tuvieron en cuenta el asentamiento indígena Hitnu denominado Cuiloto Marrero ubicado en la vereda Corocito, municipio de Puerto Rondón, con una extensión de $400 \mathrm{~m}^{2}$ y una población aproximada de 90 personas que habita fuera de los resguardos por "el desplazamiento forzado ocurrido desde el 11 junio de 2009, cuando se produjo el homicidio del docente de la comunidad por Grupos Armados" (ACNUR, 2012, p.15); ni las cinco familias Hitnu (27 personas) que habitan el casco urbano del municipio de Arauca en el sector de Bello Horizonte. Estos asentamientos Hitnu no hicieron parte de la investigación porque carecen de medios para la producción de alimento.

Los datos demográficos fueron recabados a través de cuestionarios diligenciados adulto por adulto y la información fue validada en reuniones colectivas con hombres y mujeres de la comunidad en cada uno de los asentamientos.

La descripción que se hace de los pabí y ecosistemas del territorio indígena surge de la participación directa en los recorridos y actividades necesarias en la producción y comercialización de alimentos.

La técnica de recolección de datos que permitió el mayor relevamiento de información fue la observación participante, esta se entendió durante el proceso de investigación como: "una tensión inherente que permite recordar en todo momento, que se participa para observar y que se observa 
para participar, que el involucramiento y la investigación hacen parte de un mismo proceso" (Guber, 2001, p. 21).

La observación participante, cuestionarios, recorridos, participación en actividades de producción y comercialización, y los grupos de discusión realzados durante la investigación permitieron describir contextualmente la compleja articulación de elementos asociados con la producción y acceso a los alimentos en el pueblo Hitnu.

\section{Resultados y discusión}

\section{Pueblo Hitnu: cosmovisión, organización social y contacto con lo no indígena.}

Actualmente los Hitnu habitan las sabanas de Guafal y selvas de Sarare entre los municipios de Arauca y Arauquita, departamento de Arauca, en los resguardos ${ }^{4}$ San José del Lipa, ubicado en la margen derecha del río Ele donde se encuentran las comunidades de El Romano y La Conquista, dividida esta última en cuatro asentamientos: Las Vegas, El Trapiche, Providencia y Monogarra; y el resguardo La Vorágine localizado en el margen derecho de Caño Colorado (afluente del río Ele) donde se ubica el asentamiento denominado La Ilusión. Los dos resguardos tienen una extensión total de 4.611 hectáreas $\left(46,11 \mathrm{~km}^{2}\right)$ divididas en seis asentamientos.

Los Hitnu representan el $17 \%$ de la población indígena del departamento de Arauca. Según el DANE, la población indígena del departamento es de 3.279 , equivalente al $2,24 \%$ de la población total de Arauca: 153.028 habitantes (2007, p. 79). Otros grupos indígenas del departamento son: Betoye, Chiricoa, Cuiba, Piapoco, Sikuani y Uwa

4. Territorio indígena reconocido por el Estado como propiedad colectiva, inembargable e inalienable.
La población adulta Hitnu es bilingüe casi en su totalidad (95\%), hablan el castellano y el Hitnu, esta última hace parte de la familia lingüística Guahibo $^{5}$ (Landaburu, 2005) y, de acuerdo con el Ministerio de Cultura, se encuentra en serio peligro de extinción (Mincultura, 2010, p. 205)

En los dos resguardos la población asciende a 543 personas, 270 hombres $(49,8 \%)$ y 273 mujeres $(50,2 \%)$. Se caracteriza por ser una población joven, el 58,4\% (317 personas) no supera los dieciocho años de edad, y tan solo el 5,7\%, (treinta personas) supera los cincuenta años (ver tabla 1); en el rango de los diecinueve a cincuenta años de edad se encuentra el 35,9\% de la población (196 personas).

Los asentamientos con mayor población son El Romano, Las Vegas y Monogarra, albergando un total de 368 personas; y los de menor densidad poblacional son La Ilusión, Providencia y El Trapiche con 175 personas (ver tabla 1).

La media anual de nacidos vivos durante las últimas dos décadas ha sido de 23 , el número promedio de hijos por mujer en el pueblo Hitnu es de cuatro -pueden hallarse parejas jóvenes con un solo hijo u hogares con más de siete-. Actualmente el $44 \%$ de las mujeres se encuentra en edad fértil.

La unión familiar entre los jóvenes es sugerida y acordada entre los padres, el hombre se traslada al lugar de residencia de la novia y trabajará la tierra del padre de la novia hasta que cultive su propia parcela, pabi en lengua Hitnu. En general después de la menarquia se asume que las jóvenes ya pueden tener sexo. La sexualidad está ligada fundamentalmente a la reproducción humana y la homosexualidad se reprueba. Tener una familia numerosa es sinónimo de buena salud y felicidad. 
Tabla 1. Población Hitnu por edad, sexo y asentamiento año 2015

\begin{tabular}{|c|c|c|c|c|c|c|c|c|c|c|c|c|c|}
\hline \multirow{3}{*}{ EDADES } & \multicolumn{12}{|c|}{ ASENTAMIENTOS } & \multirow{3}{*}{$\begin{array}{c}\text { Subtotal } \\
\text { x edad }\end{array}$} \\
\hline & \multicolumn{2}{|c|}{ Providencia } & \multicolumn{2}{|c|}{ Las Vegas } & \multicolumn{2}{|c|}{ Monogarra } & \multicolumn{2}{|c|}{ Trapiche } & \multicolumn{2}{|c|}{ La Ilusión } & \multicolumn{2}{|c|}{ Romano } & \\
\hline & $\mathbf{F}$ & $\mathbf{M}$ & $\mathbf{F}$ & $\mathbf{M}$ & $\mathbf{F}$ & M & $\mathbf{F}$ & M & $\mathbf{F}$ & $\mathbf{M}$ & $\mathbf{F}$ & $\mathbf{M}$ & \\
\hline $0-3$ & 4 & 2 & 8 & 14 & 5 & 4 & 2 & 2 & 7 & 7 & 9 & 11 & 75 \\
\hline $4-6$ & 1 & 3 & 4 & 10 & 11 & 5 & 5 & 0 & 5 & 6 & 9 & 12 & 71 \\
\hline $7-12$ & 3 & 2 & 9 & 15 & 12 & 7 & 7 & 6 & 5 & 7 & 20 & 4 & 97 \\
\hline $13-18$ & 4 & 0 & 7 & 4 & 12 & 7 & 1 & 1 & 8 & 8 & 7 & 15 & 74 \\
\hline $19-25$ & 3 & 3 & 7 & 7 & 7 & 7 & 0 & 2 & 6 & 5 & 6 & 7 & 60 \\
\hline $26-35$ & 3 & 4 & 8 & 5 & 5 & 6 & 5 & 3 & 6 & 7 & 6 & 6 & 64 \\
\hline $36-45$ & 2 & 2 & 3 & 13 & 3 & 2 & 0 & 3 & 5 & 4 & 6 & 5 & 48 \\
\hline $46-55$ & 1 & 0 & 6 & 1 & 2 & 3 & 2 & 1 & 2 & 1 & 2 & 3 & 24 \\
\hline $56-65$ & 0 & 3 & 3 & 3 & 0 & 1 & 0 & 1 & 1 & 0 & 1 & 2 & 15 \\
\hline $66-75$ & 0 & 0 & 1 & 1 & 0 & 2 & 0 & 0 & 1 & 0 & 0 & 2 & 7 \\
\hline $76-85$ & 0 & 1 & 0 & 0 & 0 & 0 & 0 & 0 & 0 & 0 & 1 & 0 & 2 \\
\hline $86-95$ & 0 & 0 & 1 & 0 & 0 & 0 & 0 & 0 & 1 & 1 & 0 & 0 & 3 \\
\hline $96-105$ & 0 & 0 & 0 & 1 & 0 & 0 & 0 & 0 & 0 & 0 & 0 & 0 & 1 \\
\hline $106-115$ & 0 & 0 & 0 & 0 & 1 & 0 & 0 & 0 & 0 & 0 & 0 & 0 & 1 \\
\hline Sin fecha & 0 & 0 & 0 & 0 & 1 & 0 & 0 & 0 & 0 & 0 & 0 & 0 & 1 \\
\hline $\begin{array}{l}\text { Subtotal } x \\
\text { sexo: }\end{array}$ & 21 & 20 & 57 & 74 & 59 & 44 & 22 & 19 & 47 & 46 & 67 & 67 & 512 \\
\hline $\begin{array}{l}\text { Población } \\
\text { Total: }\end{array}$ & \multicolumn{2}{|c|}{41} & \multicolumn{2}{|c|}{131} & \multicolumn{2}{|c|}{103} & \multicolumn{2}{|c|}{41} & \multicolumn{2}{|c|}{93} & \multicolumn{2}{|c|}{134} & 345 \\
\hline
\end{tabular}

Fuente: Elaboración propia.

Los Hitnu son un grupo predominantemente endogámico, de filiación patrilineal, monógamo, con un patrón de asentamiento matrilocal y una alta movilidad de familias e individuos al interior de los asentamientos. Las uniones, separaciones y recomposiciones matrimoniales son frecuentes.

El adulterio femenino es sancionado socialmente y es común que la pareja recurra a la violencia física y verbal para castigar esta conducta. Son frecuentes los relatos de mujeres agredidas por sus esposos.

Dentro de la cosmovisión Hitnu, el mundo se compone de doce tierras planas superpuestas.

La tierra en la que se encuentran los seres humanos está en la mitad de ellas, las tierras superiores están habitadas por seres mitológicos relacionadas con las diferentes enfermedades que pueden afectar a los seres humanos; las tierras de abajo están ocupadas por los blancos y caribes. (LoboGerrero \& Herrera, 1982, p. 84)

Los mitsenü ${ }^{6}$, médicos tradicionales y antigua autoridad político-religiosa, podían moverse entre todas las tierras para buscar la protección y ayuda necesarias para cumplir con sus labores, el yopo era el medio para hacer estos viajes. Las personas no mitsenü mediante el yopo pueden hacer cortas visitas a las diferentes tierras. (Sánchez, 2003, p. 24)

6. "Únicamente los hombres mitsenü que con disciplina cumplían estrictas dietas alimenticias y restricciones sexuales, podrían conseguir el dominio del yopo y de sus almas, con ello podrían desarrollar el potencial innato de tener vista clara o luminosa. Podrán ser entonces un mitsenüitphútitpenek y constituirse así en un nokobiút temible, él podría no solamente curar enfermedades graves, sino también producirla" (Plan de vida, 2011: 83) 
Algunos de los dioses que habitan estas tierras mitológicas son: Panibenú, el relámpago; Ot, dueño de este mundo; Jom ataca a los médicos tradicionales; Wuakabat defiende a los médicos tradicionales; Jomet es el sol y la luna; Nakuanú hizo los animales y el hombre; Jakü, esposa de Nakuanü; Tsetseri ayuda a los humanos; Romenü crea y esparce las enfermedades; Tchimulet hizo el alimento; Yabicok, dueño de los animales, y Morat, quien hizo la tierra.

Hay por nacimiento dos clases de seres humanos, los yakuénü y los mitsenü que con el tiempo, estricta formación y dominio del alucinógeno yopo se convertirán en médicos tradicionales. Los primeros sólo podrán tener un alma, piuiktuknát, excepcionalmente también podrán hacer viajes espirituales a través del consumo de yopo, pero estos serán muy cortos por las tierras más cercanas. En cambio los mitsenü pueden tener varias almas, a medida que procrean cada hijo es un alma para el padre y la madre, una familia podía tener varios mitsen. (Plan de Vida, 2011, p. 82)

Aunque el politeísmo pervive en los Hitnu, algunos de sus integrantes hacen alusión al dios católico como creencia individual, al mismo tiempo que es recurrente la afirmación de que ya no existen los mitsenü. El sistema político-religioso que unificaba el médico tradicional ha sido "reemplazado" por la organización del cabildo y los gobernadores.

El estatus y capacidad de regulación social de los líderes indígenas hoy no pasa por el profundo conocimiento de la medicina tradicional, como identificar las cualidades febrífugas de las plantas, ni por las labores que desempeñen con la ayuda del yopo; en buena medida los líderes (gobernadores y capitanes) son elegidos por la capacidad de mediación con la sociedad no indígena, por su habilidad de interlocución con las entidades estatales, empresas y organizaciones no gubernamentales, por el manejo del castellano como segunda lengua, y por la voluntad de no acumular los recursos públicos a los que tiene derecho la comunidad.
El relacionamiento de los líderes con empresas, entidades estatales y organizaciones no gubernamentales, genera nuevas lógicas de liderazgo, nuevos referentes de autoridad, y fortalece un sector de individuos que obtiene estatus y poder por sus habilidades de intermediación, fundamentales para acceder a recursos monetarios y alimenticios.

Estos líderes hoy no tienen funciones relacionadas con la regulación de la vida comunitaria; aunque las entidades externas a la comunidad - estatales principalmente - demandan ese rol, los líderes elegidos prefieren evadir los conflictos entre individuos o familias; sus intromisiones pueden ocasionarle problemas, además de que su idoneidad como líderes es cuestionada constantemente.

Cuando los conflictos entre familias o individuos se acrecientan, no entra en funcionamiento un dispositivo centralizado de regulación social (líderes elegidos, mitsenü o cabildos en pleno), se recurre al autoaislamiento como mecanismo de distensión y pacificación; hechos recientes fueron las siete familias que se desplazaron al sector de Yagual y las once familias que se asentaron en el sector de Camargas, ambas para evitar conflictos directos con familias de El Romano (los dos sectores hacen parte del resguardo San José del Lipa). En el caso de las familias de Yagual, su autoaislamiento implicó dejar atrás casas y cultivos. Este tipo de comportamiento (el ostracismo) es mucho más común cuando se examinan relaciones entre individuos.

Funciones asociadas con la regulación de la vida comunitaria se delegan en hombres al interior de grupos poco numerosos donde juegan un papel relevante las relaciones de parentesco, algunos ejemplos que vale pena mencionar son: Leal Moreno en Providencia, Álvaro Pinzón en El Trapiche, Luís Yustre en Camargas, Simón Parales en El Romano, y Hecho Contreras en Yagual. Estas personas pueden reconvenir en público, tomar la vocería por su grupo ante sujetos internos y externos a los asentamientos y resguardos, proponer formas de proceder al grupo 
y promover alianzas o distanciamiento con grupos similares. La delegación de estas funciones no pasa por los mecanismos de elección que estipula el ordenamiento de los cabildos.

La relación con el mundo no indígena es constante; los intercambios comerciales, el trabajo asalariado, los conflictos por animales, las tensiones generadas por el propósito de ampliar el territorio indígena, la presencia de programas estatales y acciones de organizaciones no gubernamentales; generan contactos permanentes.

Los niños y adultos mayores tienen un menor contacto con lo "no indígena", la presencia de cinco instituciones educativas de primaria en los resguardos y la dependencia a las madres genera que niños y niñas permanezcan más tiempo en las comunidades, supeditando su contacto a las visitas que diferentes entidades realizan durante todo el año; algunos adultos mayores por sus condiciones físicas también limitan su contacto a las visitas de foráneos. Cuando es necesario visitar los caseríos cercanos o el casco urbano del municipio de Arauca, las familias, padres e hijos, suelen salir juntos de los asentamientos; aunque la movilidad fuera de los resguardos es predominantemente masculina.

Es importante tener presente que, si bien el contacto con la sociedad no indígena se da de forma diferenciada, la radio juega un papel importante en la circulación de significantes y significados "no indígenas"; desde tempranas horas de la mañana y durante el anochecer, la radio, que funciona a base de baterías, permanece encendida en algunas casas. Los noticieros regionales, los partidos de la Selección Colombia y la música llanera - todo en castellano son algunos de los contenidos radiales que pululan en el territorio indígena Hitnu. Es habitual escuchar a los indígenas cantar joropo, vallenato, emular narraciones deportivas y repetir comerciales.

$\mathrm{Su}$ vestimenta tradicional era el guayuco, elaborado con algodón hilado a mano, arco y flechas. Hoy visten jeans, camisas, pantalones, blusas, pantalonetas, ropa interior, botas, tenis, sombrero o gorra, sandalias y camisetas deportivas; la ropa la adquieren a través de la compra directa o la donación de prendas por parte de población no indígena. Parafraseando a la historiadora Pilar Gonzalbo (1993) y sus estudios sobre la vestimenta indígena en Mesoamérica durante el siglo XVI: Si en el terreno de la evangelización y la castellanización definitiva se han logrado mínimos progresos, el vestido en cambio hace evidente el contacto y la incorporación de elementos de la cultura occidental en las sociedades indígenas.

\section{Sin comida y sin agua: crisis alimentaria declarada}

El pueblo Hitnu afronta una grave crisis alimentaria, de acuerdo con la información presentada en el Auto 382 de 2010 emitido por la Corte Constitucional, a través del cual se hizo seguimiento a la sentencia T-025 de $2004^{7}$ y al Auto 004 de $2009^{8}$, pudo comprobarse:

La cada vez más grave situación humanitaria de la etnia indígena Hitnu, así como la profunda crisis alimentaria [...] $71 \%$ de los niños, niñas y adolescentes valorados presentan casos de desnutrición, siendo más representativa la desnutrición crónica con un $61 \%$ mediada por el indicador talla para la edad, la cual se evidencia con retraso de crecimiento [...] Con relación a la desnutrición aguda o reciente la cual se mide con el indicador peso para talla se detectó en el $15 \%$ de los niños, niñas y adolescentes valorados [...] Por otra parte se detectó que el $12 \%$ de los niños, niñas y adolescentes presentan retraso en crecimiento con peso adecuado para la talla o adecuado índice de masa corporal. (p.5)

En esta misma dirección, en el año 2011 el Instituto Colombiano de Bienestar Familiar (ICBF) señalaba:

\footnotetext{
7. Sentencia de la Corte Constitucional donde se declaró un estado de cosas inconstitucional en la población desplazada, no solo por el hecho mismo del desplazamiento, sino también porque en la mayor parte de los casos se trata de personas especialmente protegidas por la Constitución: menores de edad, mujeres cabeza de familia, grupos étnicos y personas de la tercera edad.

8. El Auto 04 de 2009 busca la garantía y protección de los derechos fundamentales de personas e indígenas desplazados por el conflicto armado en el marco de la superación de las cosas declaradas inconstitucionales por la Sentencia 025 de 2004.
} 
Cazadores sin presas, horticultores sin tierra. Una aproximación a las formas actuales de producción y acceso al alimento en el pueblo indígena Hitnu

la baja disponibilidad de alimentos aunada a la baja cantidad de adultos para mano de obra para la realización de actividades productivas, hace que los problemas de desnutrición y enfermedades asociadas a la mala ingesta de alimentos y agua se refleje principalmente en los niños y niñas [...] de acuerdo con los parámetros de la Organización Mundial de la Salud, por medio del indicador de peso para la talla y talla para la edad, se muestra que el $13 \%$ de los niños y niñas de las comunidades indígena Hitnu, se encuentran en riesgo o situación de desnutrición aguda; además el $84,4 \%$ de los niños y niñas valorados se encuentran con retraso en crecimiento o talla baja con relación a la edad. (Burgos, 2011, p. \}

76-77)

Además de las problemáticas alrededor del acceso a los alimentos y los altos niveles de desnutrición, se suman dificultades en torno a la disponibilidad y potabilidad del agua, recurso que por sus características físicas, químicas y microbiológicas agrava la crisis alimentaria de la población.

Los resguardos San José del Lipa y La Vorágine cuentan con diecinueve puntillos ${ }^{9}$ distribuidos por asentamiento así: La Ilusión, seis; El Trapiche, tres; Monogarra, dos; Las Vegas, dos; Providencia, dos y El Romano con cuatro; se cuenta en promedio con un puntillo por cada treinta personas. De los diecinueve puntillos disponibles seis no están funcionando, ocho se encuentran en mal estado, y solo cinco se encuentran en óptimas condiciones.

Las condiciones del agua no son aptas para el consumo humano, la evaluación realizada por la Cruz Roja Colombiana Seccional Arauca en el año 2013 en cuatro puntos de captación en diferentes asentamientos del resguardo, concluyó:

Las dos primeras muestras fueron tomadas de Caño Colorado y del puntillo del Asentamiento indígena El Romano, logrando identificar que los parámetros de color, turbiedad, hierro total y coliformes totales superan el valor máximo admisible; en la muestra de puntillo en el resguardo de la Ilusión, se identificó que los

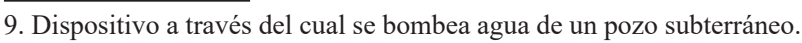

parámetros de color, turbiedad, hierro total, nitritos y coliformes totales superan el valor máximo admisible, y finalmente, la muestra del resguardo indígena de Las Vegas con el máximo nivel de riesgo, tuvo inconvenientes con parámetros como $\mathrm{pH}$, coliformes totales y E. Coli, siendo agua no apta para el consumo humano acorde con la resolución 2115 de 2007 y el decreto 1575 de 2007, dada por el Ministerio de la Protección social de Colombia. (p. 2)

Las problemáticas hasta aquí señaladas no han cambiado después de emitidos los autos que obligaban a intervenir los hechos que se declararon como inconstitucionales por la sentencia T-025 de 2004, de acuerdo con la Sala Especial de Seguimiento de la Corte Constitucional, en el caso específico del Auto 382 de 2010: "El riesgo de desaparición del pueblo [Hitnu] es más latente y grave que antes, toda vez que para febrero de 2014 no se había dado cumplimiento a las órdenes emitidas en el citado auto" (Auto 196, 2014, p. 6).

La gravedad de la crisis alimentaria se evidenció con el fallecimiento de un bebé de once meses durante el año 2016 por causa de desnutrición crónica, la hospitalización de tres menores más y el riesgo inminente para otros seis niños por razones asociadas a la desnutrición (Defensoría del Pueblo, 2016).

\section{Formas de clasificación y disputa por los recursos naturales}

Para comprender la actual situación de producción y acceso a los alimentos en los Hitnu, es necesario considerar las categorías que hacen parte del régimen de articulación de significados (Grimson, 2010) en el plano local para jerarquizar y significar las diferencias construidas históricamente alrededor de este grupo indígena.

Las formas de clasificación y jerarquización social que pudieron constatarse en campo se cimientan sobre dos límites: lo indígena (los guajibos) y la figura idealizada del llanero como su antípoda. Desde la percepción no indígena se plantea la categoría 
Guajibo como contenedora de los diferentes grupos indígenas del departamento, un grupo homogéneo al que se le asocia con ideas como: incivilidad, desorden, falta de asepsia, ausencia de normas, holgazanería, salvajismo y subdesarrollo.

Por su parte, la sociedad no indígena (sociedad mayoritaria, dominante o nacional), lejos de ser uniforme, se subdivide así misma en múltiples formas de alteridad: criollo, colono y llanero.

El colono es pensado como un advenedizo habitante del llano, proveniente de otros lugares de Colombia tan distintos como la costa Atlántica o la región central Andina; el criollo es concebido como un habitante de la sabana, trabajador infatigable de la tierra, de faena llanera, de escasos recursos económicos, sin refinamientos, ordinario (es frecuente la frase: no se ha civilizado), dicharachero, de cotizas y pantalón corto; el llanero, por su parte, se asocia con la ganadería extensiva, el latifundio y el caballo, indómito ser que domina la bravura de la naturaleza, poseedor de riqueza que se acopla con facilidad a los escenarios urbanos y rurales.

Desde el régimen clasificatorio indígena, las categorías más usadas son: el Alpinü (Blanco) y el Propio Indígena. El Alpinü es caracterizado como un grupo uniforme donde abundan los recursos económicos, el ganado, los caballos, la tierra, el joropo $^{10}$, el usufructo individual, los agiotistas, el latrocinio y la fiesta (fueron recurrentes lo relatos donde se explicitaba el robo y el oportunismo de los no indígenas); el Propio Indígena es representado como un grupo cazador, fuerte, con guayuco, arco, flechas, alegre y con cultura propia.

Estas categorías, para ambos regímenes de clasificación, se sustentan en características físicas y sobre la concepción de cierta uniformidad en el comportamiento, las maneras de hablar (modismos), habilidades para ciertos trabajos (ganadería, agricultura, cacería), indumentarias, y en el acceso a recursos como la tierra y los animales.

10. Baile típico de la región colombo-venezolana denominada como los Llanos Orientales.
El blanco que habita alrededor de los resguardos, dista de la figura del terrateniente adinerado, en su gran mayoría son campesinos empobrecidos que llegaron allí huyendo de la violencia, familias de escasos recursos que compiten con los indígenas por los recursos naturales. En Arauca como en los límites de los resguardos Hitnu la propiedad de la tierra se caracteriza por una segmentación en la que muchos propietarios poseen predios realmente pequeños y pocos propietarios poseen predios de elevadas extensiones, si bien "se presentan altas concentraciones de propiedad rural en el departamento de Arauca, la dispersión es la más alta del país después de Atlántico, Cauca y Valle" (CNMH, 2014, p.21); dicho de otro modo, predomina el minifundio.

Pero la precariedad del campesinado que vive cerca de los resguardos, en cierto modo similar a la del indígena - y que dentro de ciertos esquemas explicativos podría devenir en conjunción de intereses interétnicos -, no impide que opere el sistema de clasificación cimentado históricamente.

Tal situación - la disputa por recursos naturales - , sumado por supuesto al marcaje identitario de superioridad y laboriosidad, hace que los campesinos y colonos de la zona hagan uso indiscriminado de los recursos ubicados al interior de los resguardos. El periodo en campo permitió constatar la explotación de recursos madereros y la caza de animales con métodos lesivos para los ecosistemas del territorio indígena ${ }^{11}$.

Si bien es cierto que el discurso de la etnicidad y las modificaciones en la legislación nacional le han permitido a los indígenas un diálogo directo con funcionarios públicos y visibilizar demandas y problemáticas ante diferentes instancias estatales, las formas de clasificación social en la sociedad araucana siguen estableciendo jerarquías justificadoras de la desigualdad y de la actual situación de los Hitnu ${ }^{12}$.

11. Uso de malla no permitida para la pesca y trampas para chigüiros y cerdos de monte.

12. Vale la pena mencionar que la Antropología ha hecho valiosos aportes para pensar los usos de la identidad; las contribuciones de Manual Delgado son relevantes para dilucidar el uso de marcajes identitarios en escenarios de asimetría social: "Diferencia Cultural no es lo mismo que 


\section{Tensiones y encrucijadas: tierra, cacería y producción de alimentos}

Los Hitnu habitaron durante muchos años la extensa región occidental del departamento de Arauca denominada por los misioneros de los siglos XVII y XVIII como Selvas del Airico de Macaguane, que "se componía de un ensanchamiento de vegetación de pie de monte que parecía coincidir con la longitud de la sierra nevada del Cocuy en cuya base se encontraba una zona sumamente inundable por la presencia de numerosas fuentes hídricas, entre las que se encontraba el río Cauca, Ele y Lipa" (Berrio, 2015, p. 79). Lo habitaron con otros grupos indígenas como los Jirara, los Betoyes, los Tunebo y los Chiricoas; "este territorio tenía una extensión aproximada de $23.490 \mathrm{~km} 2$ ", según la historiadora Jane Rausch (citada por Berrio, 2015, p. 33).

De acuerdo con los Hitnu, para evitar el exterminio físico y cultural, la selva fue el refugio para evadir a los conquistadores, evangelizadores y colonos; "sólo hasta tiempos recientes, alrededor de los años cuarenta del siglo XX, los colonos comenzaron a ingresar a la región y con ellos los primero misioneros" (Plan de Vida, 2011, p. 67).

La llegada de los colonos significó, además de los intentos de evangelización y educación de los indígenas, disputas por la tierra. La cacería de indios conocida como guajibiadas se extendió como práctica para eliminar al salvaje que impedía acceder a la tierra, los jefes de hato hacían comisiones para mandar a matar indios.

José del Carmen Terán, un colono de la época que convivió con los Hitnu durante la primera mitad del siglo XX por más de veinticinco años, describe las primeras masacres:

No digamos ahorita sino en los años $20 \mathrm{o}$ 30 los jefes de hato salían hasta con treinta

desigualdad social, de hecho más que "diferencia" e "identidad" cabría hablar de "usos de la diferencia" o "usos de la identidad". Con frecuencia la identidad y la diferencia han sido usadas - o incluso inventadas con el único fin de "naturalizar" una situación de explotación, injusticia, persecución, etc" (1998, p 26). trabajadores de sus fincas; en las sabanas, en las matas de monte, donde fueran, llegaban, agarraban a los indígenas por las mechas y los partían, les quitaban la cabeza [...] Para estos lados del Lipa y del Ele, la primera masacre que me acuerdo fue la que hubo en Agua Linda, donde mataron como a seis, yo vi los cuerpos quemados. Mataron a una india y a un indio llamado Comagenare, y por Caño Colorado mataron a Aguirre el propio jefe de los Hitnu. En esa época la gente no tenía compasión mataba muchos indios. (Pinzón, 2015, p. 49)

Durante los años setenta del siglo $\mathrm{XX}$, tras una larga lucha de indígenas y colonos en contra del exterminio indígena y la expoliación de tierras, el Instituto Colombiano de la Reforma Agraria (INCORA) constituyó la Reserva Indígena Macahuan con una extensión de 18.569 hectáreas (185,69 km2) mediante la Resolución número 047 de marzo de 1974, considerando el mandato de la Ley 135 de 1961 que permitía "dotar de tierras y mejoras a las comunidades indígenas o recuperar tierras de resguardos ocupados por colonos que no pertenecen a la respectiva parcialidad..." (Artículo 54).

Pero la Reserva Indígena fue una figura provisional para la adjudicación de tierra con el propósito de garantizar los derechos de uso y usufructo, con exclusión de terceros, a las comunidades indígenas; estas fueron desapareciendo cuando el Estado decretó en 1980 la constitución de resguardos (Berrio, 2015). A pesar de la constitución de la Reservas, la ley permitía la titulación individual mediante la conformación de Unidades Agrícolas Familiares (UAF) a población no indígena.

Como puede apreciarse, el territorio Hitnu ha disminuido de manera progresiva; las selvas del Airico de Macaguane $(23.490 \mathrm{~km} 2)$, territorio ancestral en el que vivían, se redujo a la Reserva Indígena Macahuan de los años setenta $(185,69$ $\mathrm{km} 2$ ) por la presión de colonos y la política de ocupación de territorios baldíos del gobierno nacional ${ }^{13}$; y al final de la segunda mitad del

13. El mismo INCORA "para facilitar el proceso de colonización de la intendencia de Arauca y los llamados Territorios Nacionales emitió las 
siglo XX la instalación de enclaves petroleros ${ }^{14}$, el recrudecimiento del conflicto armado en la región ${ }^{15}$ y la persistente presión de los colonos, generó el más reciente achicamiento, los dos resguardos actuales $(46,11 \mathrm{~km} 2)$.

En el gran territorio que ocupaban los Hitnu fueron una sociedad seminómada de cazadores, recolectores y horticultores itinerantes, pero como puede colegirse, lejos de una visión evolucionista que supone el paso inercial producto de la teleología de la historia - de las sociedades nómadas a formas de vida sedentarias, el cambio en los patrones nomádicos de los Hitnu, se ha producido por una compleja diversidad de factores internos, externos y una historia de conflictos inter-étnicos. Los ciclos nomádicos han desaparecido y la crisis alimentaria se ha agravado por la reducción del territorio, las disputas territoriales con colonos, la presencia de grupos subversivos (FARC-EP y ELN), y la instalación de enclaves petroleros; todo ello sumado a que se les considera dueños ilegítimos de la tierra en la que viven, pues se les endilga una endémica sub-producción alimentaria, una irracionalidad económica connatural y se les concibe como esclavos del inmovilismo mental.

El sistema de tala y quema, cuando pervivían los ciclos semi-nomádicos, los convertía en sedentarios dos veces al año en la época de verano:

En sus pabí acostumbraban sembrar ocho variedades de plátano, maíz, yuca amarga y dulce, ñame, batata, tabaco y algodón. Los conucos al igual que las viviendas eran trasladados cada cuatro o cinco años, por

Resoluciones 209 de 1965, 024 de 1967 y 219 de 1972 (Santamaría, 2015: 21). Los fenómenos de violencia política en distintas regiones del interior del país, expulsaron un significativo número de individuos y familias hacia las zonas de frontera, según Gómez (1991), citando a Romero: "el ritmo del proceso colonizador fue intenso entre 1961 y 1972, la ocupación y titulación en Arauca fue de 73.187 hectáreas divididas en 1.886 predios" ( p. 8)

14. Arauca posee una de las reservas de petróleo más grande del país, conectada al oleoducto más importante de todo el territorio nacional (caño Limón Coveñas), "en 1983 la empresa estadounidense Occidental Petroleum descubrió Caño Limón, el bombeo comenzó el 18 de diciembre de 1985" (CNMH, 2014: 31))

15. "Las FARC-EP llegaron a Arauca a finales de los años setenta con el Frente 10 Guadalupe Salcedo y el ELN con el Frente Domingo Laín en los ochenta" (CNMH, 2014, p. 35) lo general a tierras de cultivo anteriores y recuperadas por la selva. (Lobo-Guerrero, 1979, p.37)

Hoy, los Hitnu poseen una agricultura principalmente de subsistencia con un sistema de siembra intercalado, no rotativo, y una pequeña red comercial con grupos no indígenas en la que se comercializa fundamentalmente los excedentes en la producción de maíz. Las incursiones de caza, aunque prevalecen, son cada vez más esporádicas por la reducción de animales al interior del territorio; practican la pesca, la recolección de moluscos (caracoles principalmente) y de alimentos de origen vegetal.

Los pabi tienen en promedio una hectárea de extensión, esta puede ser una unidad dispersa de producción de alimento, es decir, dos o tres porciones de tierra distantes una de otra, o como pasa en la mayoría de los casos, puede ser un sólo terreno cultivado. Hoy se cercan con alambre de púa para impedir el acceso de fauna silvestre y animales domésticos. Se siembra primordialmente: yuca, plátano y maíz.

Los periodos de siembra son generalmente entre los meses de abril-mayo y agosto-septiembre, teniendo como eje la temporada de lluvias que se prolonga desde el mes de abril hasta octubre; el verano se extiende desde noviembre hasta marzo. Los alimentos más cultivados son: maíz, yuca, plátano, topocho (plátano grueso y corto), banano, balasuija (plátano morado), batata (morada y blanca), ahuyama, papaya, caña de azúcar y ñame; manifiestan especial interés en adquirir semillas de frutales como: mandarina, limón, patilla ${ }^{16} \mathrm{y}$ mango.

No se practica de manera permanente la limpieza ni el uso de abonos para los cultivos, algunas familias abandonan el pabi - cuando este se subdivide en fragmentos - después de dos o tres años de uso y abren otro en un lugar distinto, el pabi viejo se deja en barbecho ${ }^{17}$.

16. Fruta conocida en otras regiones del país como sandía. 17. Sistema de cultivo que consiste en dejar de sembrar la tierra periódicamente para que se regenere. 
Los hombres trabajan en los pabi principalmente en las actividades de tala, quema, y siembra, fabrican las flechas y arcos con los que cazan; por su parte las mujeres participan activamente de la siembra, en la preparación de suelos, deshierbe y en la cosecha. Los niños y niñas son cuidados en el pabi mientras se trabaja en él. Las mujeres crean canastos para el almacenamiento y transporte del alimento con hojas de palma (mapire) o usan las hojas de platanillo.

Si bien la tierra es de todos, los lazos familiares en los asentamientos son los que permiten tener acceso a esta, se cultivará y vivirá donde se asienten los parientes consanguíneos directos o en el asentamiento de donde proceda la esposa. El pabi puede cederse o subdividirse para permitir el acceso a alimentos a otros miembros de la comunidad, principalmente familiares. El alimento producido es para la familia nuclear o extensa, aunque puede facilitarse alimento de forma no permanente a miembros de otra familia.

El actual sistema de siembra no rotativo, sumado al incremento de la población durante los últimos años y la expectativa por participar en los circuitos de comercio local, ha demandado la ampliación de los pabi, los que ha conllevado a un incremento en la tala y quema de vegetación al interior de los resguardos y un aumento del trabajo humano. Estos factores de carácter interno aunados a la presión de los colonos sobre el territorio indígena y la reducción de la tierra colectiva, generan importantes variaciones en los ecosistemas de los resguardos, en el uso de la tierra cultivable y repercuten sobre la reproducción de la fauna y flora endémica.

Los animales son cada vez más escasos, la implantación de fincas ganaderas alrededor de los resguardos, la masiva potrerización de la sabana colindante y la deforestación han generado la desaparición casi total de las zonas de aprovisionamiento de fauna para la caza. Al interior del territorio indígena pequeños matorrales y exiguos bosques de galería son los hábitats que permiten aún la reproducción de fauna silvestre. La caza se limita a especies como: tortugas, iguanas, ratones, cerdos de monte y chigüiros.

Las pesca de subsistencia depende del periodo de lluvias, algunos de los afluentes que atraviesan el territorio Hitnu no son permanentes (Caño Seco, Caño Güiriche), el nivel de algunos caños puede llegar a menos de un metro de profundidad durante el verano (Caño Azul, Caño Colorado), y el río Ele, aunque permanece con agua durante todo el año, a él no tienen acceso todos los asentamientos. La pesca se realiza con anzuelo o atarraya, y se pesca principalmente: el caribe, el bagre sapo, el bagre manta, la payara, la cuchilla y el curito.

Los animales domésticos (ver tabla 2) fueron introducidos por programas estatales con el propósito de paliar la crisis alimentaria y hacer frente a la disminución de fauna silvestre en los resguardos, animales como: gallinas, patos, reses y cerdos, pueden encontrarse en todos los asentamientos.

Tabla 2. Animales domésticos por asentamiento Hitnu.

\begin{tabular}{|l|c|c|c|}
\hline \multicolumn{1}{|c|}{ COMUNIDAD } & BOVINOS & PORCINOS & PATOS Y GALLINAS \\
\hline La Ilusión & 31 & 3 & 94 \\
\hline EI Romano & 34 & 78 & 65 \\
\hline Providencia & 17 & -- & 57 \\
\hline EI Trapiche & 15 & -- & 66 \\
\hline Las Vegas & 24 & 66 & 129 \\
\hline Monogarra & 22 & 6 & 563 \\
\hline TOTAL & 143 & 153 & 62 \\
\hline
\end{tabular}

Fuente: DPS, 2014, p. 45. 
Las expectativas con la introducción de animales domésticos era que estos se reprodujeran para servir de fuente permanente de proteína animal, pero a pesar de que los animales permiten un suministro de alimento relativamente constante, no se han multiplicado, por el contrario, "frente a la cantidad entregada inicialmente, el número de animales ha disminuido” (DPS, 2014, p.36).

Las gallinas y cerdos son consumidos, pero el ganado, aunque su carne es apetecida, se destina principalmente a la venta, además, los alimentos derivados de la leche no son producidos ni consumidos. La población en su mayoría desconoce el manejo del ganado vacuno y la cría de animales no ha hecho parte de su acervo cultural.

Es importante anotar, que si bien una buena parte de los mayores propenden por formas de producción de subsistencia menos lesivas con los micro-ecosistemas dentro del territorio indígena, al menos de manera discursiva ${ }^{18}$, las diferencias intergeneracionales son marcadas, los miembros más jóvenes se inclinan por usos más intensivos de la tierra, monocultivos a pequeña escala, introducción de ganado, cultivo de pasto, uso de agroquímicos en la producción agrícola y la búsqueda de una mayor vocación comercial.

Estas iniciativas de los miembros más jóvenes y algunos adultos, son condicionadas por propuestas agroecológicas y de sostenibilidad ambiental promovidas por diferentes entidades, y las acciones coercitivas de las guerrillas que "defienden" a los indígenas manteniendo una producción no comercial y salvaguardando el medio ambiente (la guerrilla del ELN, por ejemplo, define cuánto se puede pescar y quiénes pueden comprar los productos indígenas).

Sumado a lo dicho hasta aquí, la visión del "convivir armónico entre los ríos, los bosques, las sabanas, y la fauna con la comunidad [Hitnu-

18. Durante el trabajo de campo se pudo constatar cómo los Hitnu hacían permanente alusión a formas de producción orgánicas, hecho que contrastaba con lo que se exigía en las reuniones donde se definía vía concertación la inversión presupuestal de entidades estatales, en las que solicitaban abonos sintéticos, funguicidas y plaguicidas.
Guajibos]” (Friedemann \& Arocha, 1982, p. 85), es un discurso que en muchas ocasiones rivaliza con los ejercicios de autonomía indígena sobre sus territorios, no tiene en cuenta las diferencias intergeneracionales, las acuciantes problemáticas y las nuevas necesidades que consideran como relevantes los integrantes más jóvenes de la comunidad.

Se deifica a los Hitnu como guardianes de la naturaleza desde discursos ecologistas y antropológicos, pero se desaprueban las decisiones que se toman como sujetos sociales de derecho sobre sus territorios, muchas veces en no concordancia con los comportamientos demandados por el desarrollo sostenible, el estereotipo del nativo ecológico (Ulloa, 2005) o la construcción del Indio hiperreal (Ramos, 1992).

\section{Circulación monetaria y nueva forma de acceder al alimento}

En lo que concierne a los ingresos monetarios del pueblo hitnu, indispensables hoy para acceder a alimentos, algunas fuentes de acceso son: los jornales, el comercio, el alquiler de bienes y los subsidios estatales.

Algunos Hitnu trabajan por un jornal en fincas de blancos por diez o quince mil pesos realizando laborales agrícolas y ganaderas, otros reciben un jornal al trabajar como recolectores de hoja de coca (raspachines) en las fincas cercanas a los resguardos propiedad de blancos, por esta tarea obtienen entre doce y quince mil pesos por arroba de hoja (12 kg); de estas actividades participan ambos sexos y diferentes grupos etarios.

Las fuentes que generan mayores ingresos - e importantes variaciones en los usos del suelo - son la venta y alquiler de animales y el comercio de maíz. Los Hitnu pueden percibir entre treinta y cincuenta mil pesos por bestia al día cuando que se alquila un equino y hasta quinientos o seiscientos mil pesos cuando se vende una res. 
La venta de una carga de maíz $(100 \mathrm{~kg})$ puede representar 120.000 pesos, cuando llevan el maíz al caserío más cercano (Bocas de Ele) pueden vender en un solo día diez o doce cargas, lo que representa para la familia que lo comercializa cerca de un millón de pesos. La comercialización de cargas de maíz puede realizarse cada cuatro o cinco meses.

Los diferentes subsidios que entrega el Estado significan un valioso ingreso monetario para buena parte de la población, los subsidios provenientes de Familias en Acción y la Unidad de Víctimas ${ }^{19}$ son reclamados principalmente por las mujeres Hitnu en compañía de los niños y niñas en las dependencias estatales, estos pasan a ser un recurso familiar.

Debe aclararse que la distribución de ingresos monetarios es desigual en la comunidad, los individuos que fungen como líderes - hombre preponderantemente - al tener mayor capacidad de gestión acceden a una mayor cantidad de recursos monetarios, los docentes de los Centros de Educación Indígena en los resguardos tienen un ingreso fijo, y no todas las familias cuentan con las herramientas y fuerza de trabajo para participar de las redes de comercio agropecuario.

Las formas de producción y acceso al alimento en el pueblo Hitnu se complementan con la participación en dinámicas salariales y comerciales a pequeña escala en estrecha relación con la sociedad no indígena que permiten la compra e intercambio de alimentos.

\section{Asistencia alimentaria y dieta Hitnu}

La base de la alimentación Hitnu son el plátano, el maíz, la yuca, el arroz y la pasta de trigo; los tres primeros se cultivan en los pabí, los demás, como muchos otros alimentos frecuentes en la dieta actual de la comunidad, se obtienen por medio de la asistencia alimentaria que suministran diferentes entidades estatales.
Como se ha señalado en secciones anteriores, la escasa variedad de alimento en los pabi y la baja productividad de estos por el uso cada vez más intensivo, la ausencia de la práctica del abono y la imposibilidad de la rotación de la tierra cultivada por la reducción del territorio colectivo, sumado a la disminución de las presas y bosques para recolectar alimento; genera que la dieta Hitnu se fundamente, casi exclusivamente, en carbohidratos (ver tabla 3, columna asistencia alimentaria y producción actual).

Tal situación ocasiona que los alimentos autóctonos de la dieta Hitnu desaparezcan progresivamente, pasando a ser reemplazados por alimentos provenientes de la asistencia alimentaria transitoria que brinda el Estado. La producción de alimento al interior de los resguardos es insuficiente para suplir las necesidades alimentarias de la población.

Es importante señalar que según las Naciones Unidas (2015) "la asistencia alimentaria transitoria que entrega el Estado a través de la Unidad para la Atención y Reparación Íntegra a las Víctimas (UARIV) a los Hitnu para dar cumplimiento al Auto 382 de 2010, no cumple el enfoque diferencial que manda la ley" (p.23), al mismo tiempo que buena parte del alimento suministrado es desechado por no considerársele comida (blanquillo, maíz en lata, garbanzo, entre otros) o sirve de sustento para los animales.

Una atención alimentaria que no considera la dimensión cultural de la alimentación y que pretende resolver la seguridad alimentaria de la población colocando a circular exclusivamente alimentos dentro de los resguardos, sólo impide, de manera temporal, que los problemas hasta aquí descritos no tomen otras dimensiones; pero estos, inevitablemente, se seguirán incubando y profundizando, ocasionando muy probablemente mayores repercusiones en el corto y mediano plazo. La atención alimentaria, por si sola, no hace mella en la abigarra urdimbre de fenómenos que hoy generan la grave crisis alimentaria del pueblo Hitnu.

19. Los subsidios se entregan por parte del Estado buscando entre muchos objetivos: cuidado y adecuada nutrición de los niños, atención en salud y permanencia escolar. 
Tabla 3. Tabla comparativa de alimentos: alimentos autóctonos y a los que se tiene acceso vía asistencia alimentaria y producción propia.

\begin{tabular}{|c|c|c|}
\hline Grupo & Autóctonos & $\begin{array}{c}\text { Asistencia alimentaria y producción } \\
\text { actual }\end{array}$ \\
\hline Cereales & Maíz & $\begin{array}{l}\text { Maíz enlatado, arroz, cebada, avena, trigo, } \\
\text { pastas. }\end{array}$ \\
\hline Cárnicos & $\begin{array}{l}\text { Tortuga, babilla, pescados, chácharo } \\
\text { (cerdo), cafuche (cerdo), chisas (gusanos), } \\
\text { caracol, araguato (mico aullador), } \text { picure }^{20}, \text { lapa }^{21}, \text { ratón de palma, mato } \\
\text { (lagartija grande), chigüiro }^{22} \text {, cachicamo } \\
\text { guacharaca (ave) oso hormiguero, oso } \\
\text { palmero. }\end{array}$ & $\begin{array}{l}\text { Cárnicos enlatados (salchichas, jamoneta, } \\
\text { atún, sardina), cerdo, pollo, res, y cárnicos } \\
\text { autóctonos una muy pequeña proporción } \\
\text { (iguana, cerdo, tortuga, chigüiro). }\end{array}$ \\
\hline Endulzantes: & Caña, miel de abeja. & $\begin{array}{l}\text { Azúcar refinada, panela, caña, endulzantes } \\
\text { artificiales. }\end{array}$ \\
\hline Lácteos & No se encontró ninguna referencia. & Leche en polvo. \\
\hline Tubérculos & Batata, yuca, ocumo, mañoco. & Yuca, ñame, papa, batata. \\
\hline Leguminosas & No se encontró ninguna referencia. & Lenteja, garbanzo, blanquillo ${ }^{24}$, frijol. \\
\hline Frutas & $\begin{array}{l}\text { Papaya, banano, guayaba, guamo, mamón, } \\
\text { guanábana, caimito de palma. }\end{array}$ & $\begin{array}{l}\text { Banano, naranja, piña, papaya } \\
\text { (componente dietario en muy baja } \\
\text { proporción). }\end{array}$ \\
\hline Plátano & Sembraban ocho variedades de plátano & $\begin{array}{l}\text { Harina de plátano, topocho (plátano grueso } \\
\text { y corto), y balasuija (plátano morado). }\end{array}$ \\
\hline Vegetales & No se encontró ninguna referencia. & $\begin{array}{l}\text { Zanahoria en lata, alverja en lata, } \\
\text { habichuela en lata. }\end{array}$ \\
\hline Condimentos & No se encontró ninguna referencia. & Ajo en polvo, canela. \\
\hline
\end{tabular}

Fuente: Elaboración propia con base a datos levantados en campo, los trabajos etnográficos de Lobo Guerrero (1979) y el Plan de vida Peknarbüchi Jitne (2011).

\section{Conclusiones}

La conjunción de múltiples factores a lo largo de la historia reciente del pueblo Hitnu ha generado una sedentarización inducida con formas de producción precarias e inestables, que para buena parte de la sociedad araucana no son más que el resultado ineluctable de la "diferencia cultural": el ser guajibos explicaría por sí sólo (la cultura hecha esencia) la situación alimentaria de la comunidad Hitnu.

La asistencia alimentaria por su parte, si bien se convierte en un paliativo que indudablemente aminora conflictos sociales, coloca la atención en un único punto de la compleja situación Hitnu: la escasez de alimentos, pero soslaya variables primordiales para comprender e intervenir sobre la problemática. Además, al no considerar un enfoque

20. Roedor conocido en otras regiones del país como guatín.

21. Conocido en otras regiones del país como guagua.

22. El roedor más grande del planeta, es también conocido con el nombre de capibara.

23. Conocido en otras regiones del país como armadillo.

24. Frijol pequeño de color blanco. 
Cazadores sin presas, horticultores sin tierra. Una aproximación a las formas actuales de producción y acceso al alimento en el pueblo indígena Hitnu

diferencial, introduce variaciones significativas en la dieta indígena.

Por otro lado, la expansión de la ganadería, la potrerización de las zonas aledañas a los resguardos, la disminución sistemática del territorio indígena, y la tensión permanente con los blancos que desean extraer recursos y ocupar tierras en los sectores contiguos al territorio indígena, generan una disminución notable de la fauna y flora, así como una pérdida progresiva de los ecosistemas en los que se reproducen animales y plantas base de la dieta Hitnu.

Las formas actuales de producción y acceso al alimento en los Hitnu están signadas por la capacidad de mediación con el mundo noindígena, la mercantilización de sus bienes, la circulación de recursos monetarios y la asistencia alimentaria transitoria que entidades estatales suministran. Lejos de la sociedad indígena autárquica, la alimentación indígena esta anudada a articulaciones complejas que además de obligarnos a pensar fuera de los marcos explicativos que suponen cierta insularidad de los grupos indígenas, debe llevarnos a replantear nociones estáticas de la identidad y de las prácticas ancestrales de las sociedades indígenas.

Es apremiante prestar atención a variables como las representaciones sociales que reproducen actores que intervienen directa o indirectamente sobre la población que habita los resguardos, al mismo tiempo que sopesar de mejor manera alternativas como la horticultura y la producción pecuaria en sociedades sin tradiciones asociadas a estas prácticas.

Fortalecer la participación y autonomía indígena, aunque esta no se ciña a los ideales conservacionistas de territorios autárquicos o del desarrollo sustentable que prohíjan ciertos sectores sociales o la misma legislación nacional; y reconocer las diferencias intergeneracionales, los conflictos internos y las desigualdades en la capacidad de agencia de los miembros de la comunidad, es fundamental para generar procesos de organización y cohesión comunitarios que surjan de las actuales representaciones y prácticas Hitnu para dar solución a la crisis alimentaria.

\section{Referencias bibliográficas}

Alto Comisionado de las Naciones Unidas para los Refugiados ACNUR. (2012). Situación de derechos individuales y colectivos del Pueblo Hitnu resguardos La Vorágine y San José del Lipa. Arauca: ACNUR.

Berrio, S. (2015). "Pueblo Hitnu: Un contexto de desencuentros". Conflictos ambientales Interétnicos $y$ Territoriales (Tesis de maestría). Universidad Nacional de Colombia, Medellín, Colombia.

Burgos, L. (2011). Aproximación etnográfica al pueblo Jitnu de Arauca. Guía para un acercamiento intercultural. Arauca: ICBF.

Centro Nacional de Memoria Histórica CNMH. (2014). Recordar para reparar. Las masacres de Matal de Flor Amarillo y Corocito en Arauca. Bogotá D.C: CNMH.

Colombia. (11 de marzo de 2014). Sala Especial de la Corte Constitucional. Auto de Seguimiento a la Sentencia T-025 de 204 en el marco de cosas declaradas inconstitucional en materia de desplazamiento forzado.

Colombia. (2010). Sala Especial de la Corte Constitucional. Auto 382 por el cual se toman medidas de protección a derechos fundamentales de personas e indígenas desplazados y se hace seguimiento a la crisis humanitaria, alimentaria y de salubridad del pueblo Hitnu.

Colombia. (1 de julio de 2014). Corte Constitucional. Auto 196 por el cual se solicita información al Gobierno Nacional sobre las medidas implementadas para la prevención, atención y protección a la población indígena, en el marco del seguimiento a la sentencia T-025 de 2004, y los Autos 004 de 2009, 382 de 2010, 174 de 2011, 173 de 2012 y 051 de 2013.

Cruz Roja Colombiana. (2013). Apoyo para la respuesta en salud y saneamiento básico ante la emergencia por desbordamiento del río Ele municipio de Arauca, departamento de Arauca. Arauca. 
Departamento Administrativo Nacional de Estadística DANE. (2007). Plan Estadístico del Departamento de Arauca. Bogotá. Colombia. Recuperado de https://www.dane.gov.co/files/sen/ planificacion/planes/Arauca_2007.pdf

Defensoría del Pueblo.(2016) Alerta de la Defensoría por desnutrición infantil en Arauca. Recuperado de http://www.defensoria.gov.co/es/nube/enlosmedios/4747/Alerta-de-laDefensor\%C3\%ADa-pordesnutrici $\%$ C3\%B3n-infantil-en-Arauca.htm.

Delgado, M. (1998). Dinámicas identitarias y espacios públicos. Afers Internacionals, 32(44), 17-33.

Departamento de Prosperidad Social DPS. (2014). Seguridad alimentaria en el pueblo Hitnu: Línea base y propuesta de plan de seguridad alimentaria. Arauca: DPS.

Fabre, A. (2005). Diccionario etnolingüístico y guía bibliográfica de los pueblos sudamericanos. Argentina: Siglo XXI editores.

Friedemman, N. \& Arocha, J. (1982). Herederos del Jaguar y la Anaconda. Bogotá D.C: Carlos Valencia Editores.

Gómez, A. (1991). Llanos Orientales: Colonización y conflictos inter-étnicos, 1870-1970. Revista Instituto Colombiano de Antropología, 23(2), 79-105.

Gonzalbo, P. (1993). Vestir al desnudo. Un acercamiento a la ética y la estética del vestido en el siglo XVI novohispano. En Gonzalbo, P. (Ed), Herencia española en la cultura material de las regiones de México: Casa, vestido y sustento (pp. 329-349). México: Editorial El Colegio de Michoacán.

Grimson, A. (2010). Cultura, identidad: Dos nociones distintas. identidades Sociales, 16(1), 63-79.

Guber, R. (2001) La etnografia. Método, campo y reflexividad. Bogotá D.C: Grupo editorial norma.

Ministerio de Salud y Protección Social (2016). Análisis de la situación de salud (ASIS) Colombia. Dirección de Epidemiologica y Demografia. Bogotá. Recuperado de https://www. minsalud.gov.co/sites/rid/Lists/BibliotecaDigital/
RIDE/VS/ED/PSP/asis-colombia-2016.pdf Landaburu, J. (2005). Las lenguas indígenas de Colombia. Revista Amerindia, 6(29), 4-22.

Lobo-Gurrero, M. (1979). El Macaguane y la familia lingüistica guahibo (Tesis de Grado). Universidad Nacional de Colombia, Bogotá, Colombia.

Lobo-Guerrero, M. \& Herrera, X. (1982). Estudio de la Antropología Medica entre los indígenas y colonos del medio río Ele (Arauca). Informe Final. Bogotá, Colombia: Colciencias.

Lobo-Guerrero, M. \& Herrera, X. (1989). Salud Medicina y Antropología. Revista Universidad Nacional de Colombia, 18(30), 13-23.

Ministerio de Cultura. (2010). Caracterización de los pueblos indígenas en riesgo. Dirección de poblaciones. Bogotá. Recuperado de http://www. mincultura.gov.co/areas/poblaciones/pueblosindigenas/Documents/Compilado\%20de\%20 Caracterizaciones\%20Pueblos\%20en\%20Riesgo.pdf

Naciones Unidas. (2015). Situación del Derecho del Pueblo Hitnu a disfrutar del más alto nivel posible de salud mental y física. Bogotá. Colombia.

OXFAM. (2015). Colombia: Las falacias detrás de las Zidres, una ley de subdesarrollo rural. Recuperado de https://www.oxfam.org/es/colombia-las-falaciasdetras-de-zidres-una-ley-de-subdesarrollo-rural.

Plan de Vida Peknarbüchi Jitne. (2011). Secretaría de Gobierno y Seguridad Ciudadana. Gobernación de Arauca. Arauca. Colombia.

Pinzón, N. (2015). José del Carmen Terán, una historia de vida para contar. Memorias y relatos del llano. Bogotá, Colombia: Editorial Ciespaz.

Posso, C. (2008, octubre 18) ¿A quién creer? El Espectador. Recuperado de http://www.elespectador. com/impreso/articuloimpreso86113-quien-creerle.

Ramos, A. (1992). El indio hiperreal. Serie antropología, 8(3), 1-18.

Sánchez, L. (2003). Caracterización de los grupos humanos rurales de la cuenca hidrográfica del Orinoco en Colombia. Bogotá: Instituto Alexander Von Humboldt. 
Cazadores sin presas, horticultores sin tierra. Una aproximación a las formas actuales de producción y acceso al alimento en el pueblo indígena Hitnu

Santamaría, A. (2015). Caracterización de los conflictos socio-ambientales generados por la industria petrolera en la zona de influencia del ecosistema de Esteros y Laguna del Lipa, Departamento de Arauca. Bogotá: Fundación Luterana.
Ulloa, A. (2005). Las representaciones sobre los indígenas en los discursos ambientales y de desarrollo sostenible. En D. Mato \& Daniel M. (Coord.), Políticas de economía, ambiente y sociedad en tiempos de globalización (pp. 89-109) Caracas: Universidad Central de Venezuela. 